\title{
Antidepressant-like properties of sarizotan in experimental Parkinsonism
}

\author{
Xiaoqun Zhang $\cdot$ Martin Egeland $\cdot$ Per Svenningsson
}

Received: 15 August 2010 / Accepted: 9 May 2011 / Published online: 7 June 2011

(C) The Author(s) 2011. This article is published with open access at Springerlink.com

\begin{abstract}
Rationale Depression and anxiety are common symptoms in Parkinson's disease for which there are no optimal treatments. Sarizotan, an agonist at serotonin receptors and partial agonist at dopamine $\mathrm{D}_{2}$-like receptors, has shown antidyskinetic effects in Parkinson's disease. Based on its pharmacological profile, we hypothesized that sarizotan could also have antidepressant-like properties.

Objectives Examine effects of sarizotan on behavioral and histological measures known to be regulated by established antidepressants in normal and unilaterally 6-hydroxydopaminelesioned rats.

Results Sarizotan was found to significantly reduce immobility in the modified forced swim test, a measure of antidepressant-like activity, but had no effects on thigmotaxis or corner time, measures of anxiety-like behavior, in the unilaterally 6-hydroxydopamine-lesioned rats. At the same dose, sarizotan counteracted L-DOPA/benserazideinduced supersentitized rotational behavior and dyskinesias without significantly affecting L-DOPA/benserazide-induced locomotion. At the histological level, sarizotan alone or in combination with L-DOPA/benserazide stimulated cell proliferation, measured by bromodeoxyuridine incorporation or Ki-67 staining, both in the subgranular zone of the dentate gyrus and in the subventricular zone of the striatum in the 6-hydroxydopamine-lesioned hemisphere. Likewise, combined sarizotan and L-DOPA/benserazide treatment
\end{abstract}

Xiaoqun Zhang and Martin Egeland contributed equally to this study.

X. Zhang $\cdot$ M. Egeland $\cdot$ P. Svenningsson $(\bowtie)$

Translational Neuropharmacology, Department of Clinical

Neuroscience, Center for Molecular Medicine,

Karolinska Institute,

17176 Stockholm, Sweden

e-mail: per.svenningsson@ki.se stimulated doublecortin levels in the subgranular zone of the dentate gyrus.

Conclusions These significant effects of sarizotan in the modified forced swim test and on cell proliferation are reminiscent of those found after various antidepressant therapies. These data suggest that sarizotan may have some antidepressant-like and restorative properties in Parkinsonism.

Keywords 6-hydroxydopamine · Parkinson's disease . Bromodeoxyuridine $\cdot$ Ki-67 · Doublecortin · Serotonin . Modified forced swim test

\section{Introduction}

Sarizotan was developed as a putative atypical antipsychotic agent and exhibits high affinities to serotonin 5- $\mathrm{HT}_{1 \mathrm{~A}}$ receptors and dopamine $\mathrm{D}_{4}>\mathrm{D}_{3}>\mathrm{D}_{2}$ (i.e., $\mathrm{D}_{2}$-like) receptors with the profile of a $5-\mathrm{HT}_{1 \mathrm{~A}}$ receptor agonist and $\mathrm{D}_{2}$-like receptor partial agonist (Bartoszyk et al. 2004). Studies in animal models of Parkinsonism revealed that sarizotan has antidyskinetic properties and could represent a new approach for the treatment of extrapyramidal motor complications in Parkinson's disease (PD). Indeed, when sarizotan was systemically administered alone or together with 3,4dihydroxy-L-phenylalanine (L-DOPA) to rats rendered Parkinsonian by unilateral 6-hydroxydopamine (6OHDA)-lesioning or to 1-methyl-4-phenyl-1,2,3,6-tetrahydropyridine (MPTP)-treated nonhuman primates, it attenuated the shortening in motor response duration and choreiform dyskinesias induced by chronic L-DOPA treatment (Bibbiani et al. 2001). These antidyskinetic effects of sarizotan occurred without any effects on Parkinsonian severity or on the antiparkinsonian response to L-DOPA. 
However, the human studies on the antidyskinetic effects of sarizotan have not been conclusive (Bara-Jimenez et al. 2005; Goetz et al. 2007).

Depression and anxiety are common non-motor symptoms in PD (Chaudhuri et al. 2006). Despite the high incidence of these co-morbidities in PD, there are no optimized treatments for these conditions. It is known that $5-\mathrm{HT}_{1 \mathrm{~A}}$ receptors are critically involved in the regulation of mood and emotionality and are thought to mediate some therapeutic actions of established antidepressants including selective serotonin reuptake inhibitors (SSRIs) (see, e.g., Savitz et al. 2009). Moreover, SSRIs, tricyclic antidepressants, and electroconvulsive shock therapy, all increase post-synaptic $5-\mathrm{HT}_{1 \mathrm{~A}}$ receptor signaling through direct or indirect effects (Savitz et al. 2009). Thus, based on its stimulatory properties of 5- $\mathrm{HT}_{1 \mathrm{~A}}$ receptors, sarizotan could exert antidepressant and anxiolytic actions.

$5-\mathrm{HT}_{1 \mathrm{~A}}$ receptor knockout mice display increased anxiety-related behavior, which cannot be rescued by antidepressant drug treatment (Ramboz et al. 1998). Moreover, 5- $\mathrm{HT}_{1 \mathrm{~A}}$ receptor knockout mice are insensitive to the neurogenic effects of fluoxetine, a commonly prescribed antidepressant and SSRI (Santarelli et al. 2003). Likewise, selective antagonism at $5-\mathrm{HT}_{1 \mathrm{~A}}$ receptors decreases cell proliferation (Radley and Jacobs 2002) and, vice versa, stimulation of $5-\mathrm{HT}_{1 \mathrm{~A}}$ receptors increases cell proliferation (Banasr et al. 2004). Interestingly, the numbers of proliferating cells in the subventricular zone (SVZ) of the striatum and in the subgranular zone (SGZ) of the dentate gyrus are reduced in post-mortem brains of individuals with PD (Hoglinger et al. 2004). Such reductions could also be found in experimental Parkinsonism in rodents and restored by treatment with L-DOPA or selective agonists at $\mathrm{D}_{2}$-like receptors (Hoglinger et al. 2004; Yang et al. 2008), with no mention of effects of 5-HT receptor ligands.

The hypotheses underlying the present study were that sarizotan, due to its pharmacological profile, may exert antidepressant- and/or anxiolytic-like behavioral effects and stimulate cell proliferation in neurogenic brain regions in experimental Parkinsonism. We therefore used both normal and unilaterally 6-OHDA-lesioned rats and examined the behavioral effects of sarizotan in the modified forced swim test (mFST), a measure of antidepressant-like activity, and on thigmotaxis or corner time, measures of anxiety-like behavior. For comparison, behavioral effects of saline, sarizotan, or L-DOPA/benserazide alone, or in combination, on rotations, abnormal involuntary movements (AIMs) and motor activity were measured in the unilaterally 6-OHDAlesioned rats. We also examined cell proliferation and neurogenesis in the neurogenic brain regions, SVZ and SGZ, in unilaterally 6-OHDA-lesioned rats chronically treated with saline, sarizotan, or L-DOPA/benserazide alone or in combination. Bromodeoxyuridine (BrdU), an exogenous compound which incorporates into the DNA of dividing cells, and Ki-67, an endogenous protein expressed only during mitosis, were used to measure cell proliferation. Doublecortin (DCX), a protein present in immature neurons, was used to measure neurogenesis.

\section{Materials and methods}

Animals, surgery, and pharmacological treatment

Male Sprague-Dawley rats (150 g; Scanbur, Sweden) were used for this study and housed in separate air-conditioned rooms (12-h dark/light cycle) at $20^{\circ} \mathrm{C}$ and a humidity of $53 \%$. Experiments were performed in agreement with the European Communities Council Directive of 24 November 1986 (86/609/EEC) on the ethical use of animals and were approved by the local ethical committee at Karolinska Institute.

In most of the experiments, unilaterally 6-OHDAlesioned rats were used to mimic aspects of Parkinsonism. Unilateral 6-OHDA lesioning of nigral dopaminergic axons was performed as previously described (Zhang et al. 2008). Briefly, rats were anesthetized with ketamine $(80 \mathrm{mg} / \mathrm{kg}$, i.p.; Parke-Davis, Boxmeer, Netherlands)/xylazine $(10 \mathrm{mg} / \mathrm{kg}$, i.p.; Bayer, Kiel, Germany), pretreated with desipramine ( $25 \mathrm{mg} / \mathrm{kg}$, i.p.; Sigma, Stockholm, Sweden) and pargyline $(5 \mathrm{mg} / \mathrm{kg}$, i.p.; Sigma), placed in a stereotaxic instrument and injected with 6-OHDA $(2.5 \mu \mathrm{l}$ of a $5 \mathrm{mg} / \mathrm{ml}$ solution; Sigma) into the medial forebrain bundle of the right hemisphere ( $\mathrm{AP}-2.8 \mathrm{~mm}, \mathrm{ML}-2.0 \mathrm{~mm}$ and $\mathrm{V}-9.0 \mathrm{~mm}$ ). Two weeks after unilateral 6-OHDA lesioning, rats were administered with apomorphine (1 mg/kg, i.p; Sigma), and their contralateral rotations were measured over 30 mins. Only rats which rotated contralaterally more than 100 times were included in further experiments. The rats were then equally distributed in groups based on apomorphine-induced rotations for the subsequent experiments. The efficacy of the dopamine denervation was verified post-mortem by measurements of the striatal levels of tyrosine hydroxylase (TH) and dopamine transporter (DAT). Four weeks after the surgery, the animals were used for the experiments. 6-OHDA-lesioned rats were treated with saline $(n=15)$, and sarizotan $(1 \mathrm{mg} / \mathrm{kg}, n=6$ and $2.5 \mathrm{mg} / \mathrm{kg}$, i.p., Merck KGA, $n=16$ ) in the acute experiments studying mFST and motor activity. We also used normal rats which were treated with saline $(n=6)$ and sarizotan $(1 \mathrm{mg} / \mathrm{kg}, n=6$ and $2.5 \mathrm{mg} / \mathrm{kg}$, i.p., $n=6)$ in these acute behavioral experiments. In the chronic experiments studying rotation, AIMs, motor activity, cell proliferation, and neurogenesis, 6-OHDA-lesioned rats were treated with saline $(n=4)$, sarizotan $(2.5 \mathrm{mg} / \mathrm{kg}$, i.p., $n=5)$, L-DOPA/ 
benserazide (10/7.5 mg/kg, i.p., Sigma, $n=9)$ alone, or sarizotan (2.5 mg/kg, i.p.) + L -DOPA/benserazide $(10 / 7.5 \mathrm{mg} / \mathrm{kg}$, i.p., $n=5)$ in combination. Throughout these studies, the methyl ester form of L-DOPA was used. The choices of dosages of sarizotan and L-DOPA were based on previous experiments (Bibbiani et al. 2001; Lundblad et al. 2004). At the end of the chronic experiment, the rats were anesthetized (see above) and perfused (intracardially with $4 \%$ paraformaldehyde) $2 \mathrm{~h}$ after the last injection.

\section{Behavioral experiments}

\section{MFST to measure antidepressant-like activity}

We used the mFST (Lucki 1997), which, in comparison to Porsolt's original test (1977), does not allow the rats to balance on their tails. It is a 2-day procedure, and we studied both normal and unilaterally 6-OHDA-lesioned rats. (The 6-OHDA-lesioned rats were equally distributed in groups based on apomorphine-induced rotations in $30 \mathrm{~min}$ (saline 137.6 \pm 15.7 ; sarizotan (1 $\mathrm{mg} / \mathrm{kg}$ ) 145.8 \pm 12.9 ; sarizotan $(2.5 \mathrm{mg} / \mathrm{kg}) 139.2 \pm 15.1))$. On the first day, the rats were gently placed individually in a vertical Plexiglas cylinder (height $45 \mathrm{~cm}$, diameter $19 \mathrm{~cm}$ ) filled with $26^{\circ} \mathrm{C}$ water at a depth $(35 \mathrm{~cm})$ that makes it impossible for the rat to reach the bottom with hind paws. The animals were removed from the water after $15 \mathrm{~min}$ and dried before they returned to their home cages. The water was changed after each session. On the second day, the rats were placed in the same cylinders for $5 \mathrm{~min}, 30 \mathrm{~min}$ postinjection of saline or sarizotan ( $1 \mathrm{mg} / \mathrm{kg}$ and $2.5 \mathrm{mg} / \mathrm{kg}$, i.p.). The sessions were video-recorded and an observer, blind to the treatment, subsequently scored the behavior of the animals. According to the established criteria (Porsolt et al. 1977; Lucki 1997), the rat was judged to be immobile when it floated passively, making only small movements to keep its nose above the surface. Moving limbs to break through the water, climbing, or diving were scored as activity. After 1 week of washout, the locomotion of same rats was also tested for $5 \mathrm{~min}$ in open-field boxes $30 \mathrm{~min}$ postinjection of saline or sarizotan ( $1 \mathrm{vs.} 2.5 \mathrm{mg} / \mathrm{kg}$, i.p.). The presented data are pooled from two experiments. In one experiment, six animals were used in each studied group. In another experiment, only unilaterally 6OHDA-lesioned rats treated with saline $(n=9)$ or sarizotan $(2.5 \mathrm{mg} / \mathrm{kg} ; n=10)$ were examined. The data for the latter two groups were similar between the two experiments and therefore it was justified to pool them.

\section{Thigmotaxis and corner time to measure anxiety-like activity}

Thigmotaxis and corner time in an open-field measure the conflict of an animal to enter open spaces and reflect anxiety- like responses. Square open-field arenas $(680 \times 680 \times$ $450 \mathrm{~mm}$ ) were used to measure thigmotaxis and corner time (Ericson et al. 1991). The arenas were equipped with two rows of photocells, sensitive to infrared light, placed 40 and $125 \mathrm{~mm}$ above the floor. The photocells were spaced $90 \mathrm{~mm}$ apart, and the last photocell in a row was spaced $25 \mathrm{~mm}$ from the wall. The open field was enclosed in a ventilated and sound-attenuating box. The variables recorded were horizontal activity (all interruptions of photo beams in the lower rows), peripheral activity (all interruptions of photo beams in the lower rows closest to the walls), and time spent in the corners of the boxes. Thigmotaxis is the ratio between peripheral and horizontal activities. These studies were performed only unilaterally 6-OHDA-lesioned rats and measurements were done for $10 \mathrm{~min}, 35 \mathrm{~min}$ postinjection of saline $(n=4)$, sarizotan $(n=5$, $2.5 \mathrm{mg} / \mathrm{kg}$, i.p.), L-DOPA/benserazide $(n=9,10 / 7.5 \mathrm{mg} / \mathrm{kg}$, i.p.) alone, or sarizotan $(2.5 \mathrm{mg} / \mathrm{kg}$, i.p. $)+\mathrm{L}-\mathrm{DOPA} /$ benserazide $(10 / 7.5 \mathrm{mg} / \mathrm{kg}$, i.p., $n=5)$ in combination acutely or after 24 days of treatment. (The 6-OHDA-lesioned rats were equally distributed in groups based on apomorphineinduced rotations in $30 \mathrm{~min}$ (saline 210.3 441.0 ; sarizotan $199.6 \pm 38.5$; L-DOPA/benserazide $239.9 \pm 35.9$; sarizotan + L-DOPA $232.4 \pm 42.7$ ).

\section{Measurements of rotations, AIMs, and motor activity}

Measurements of rotations, AIMs, and motor activity were performed sequentially in the same animals acutely and after 24 days of treatment (and are identical to the animals used for studies of thigmotaxis and corner time). For measurements of rotations and AIMs, unilaterally 6OHDA-lesioned rats were treated with saline $(n=4)$, sarizotan $(n=5)$, L-DOPA/benserazide $(n=9)$ alone, or sarizotan + L-DOPA/benserazide $(n=5)$ in combination and placed in individual cages. The number of ipsilateral and contralateral rotations was thereafter counted for $30 \mathrm{~min}$ on days 1 and 24 to measure rapid responses to L-DOPA, which are known to supersensitize after chronic L-DOPA administration (Bibbiani et al. 2001). Immediately after the quantification of rotational behaviors, the incidence of AIMs was scored for $5 \mathrm{~min}$ (Zhang et al. 2008). This procedure was adapted from a validated rodent scale (Lundblad et al. 2004). The AIMs were classified into four subtypes: Forelimb, Orofacial, Axial, and Locomotive behaviors. Enhanced manifestations of normal behaviors such as grooming, gnawing, rearing, and sniffing were not included in the rating. The severity of each AIM subtype was assessed using scores from 0 to 4 (0: absent, 1: occasional, i.e., present less than $50 \%$ of the time; 2: frequent, i.e., present more than $50 \%$ of the time; 3 : continuous, but interrupted by strong sensory stimuli and 4: continuous, not interrupted by strong sensory stimuli). Total 
horizontal and rearing activities were then measured in the same animals in the open-field arenas (described above) for $10 \mathrm{~min}$, i.e., $35 \mathrm{~min}$ postinjection of saline, sarizotan, LDOPA/benserazide alone or sarizotan $+\mathrm{L}-\mathrm{DOPA} /$ benserazide in combination.

\section{BrdU labeling and tissue processing}

To assess levels of cell proliferation by the BrdU procedure, the abovementioned rats which had been treated chronically with saline, sarizotan, L-DOPA/benserazide, or sarizotan+ L-DOPA/benserazide in combination and studied behaviorally in terms of thigmotaxis, corner time, rotations, AIMs, and motor activity were repeatedly administered with BrdU. Individual doses of $50 \mathrm{mg} / \mathrm{kg}$ BrdU (Sigma) i.p. were given every $2 \mathrm{~h}$ for a total of four injections over $8 \mathrm{~h}$. Rats were then sacrificed $24 \mathrm{~h}$ after the last BrdU injection. Rats were deeply anesthetized using a combination of ketamine $(80 \mathrm{mg} / \mathrm{kg}$; i.p.) and xylazine $(10 \mathrm{mg} / \mathrm{kg}$; i.p.) in sterile $0.9 \%$ saline and were then perfused with phosphate buffered saline (0.1 M PBS, pH 7.4) followed by perfusion with 4\% paraformaldehyde (Sigma) in $0.1 \mathrm{M}$ PBS. Entire brains were post-fixed in the same fixative overnight at $4^{\circ} \mathrm{C}$ and then cryoprotected by immersion in $30 \%$ sucrose in $0.1 \mathrm{M}$ PBS at $4{ }^{\circ} \mathrm{C}$ for $48 \mathrm{~h}$. Brains were finally frozen and sectioned at $40 \mu \mathrm{m}$ using a cryostat at $-20^{\circ} \mathrm{C}$ (Leica CM1850, Nussloch, Germany) and stored in 0.1 M PBS at $4^{\circ} \mathrm{C}$ until staining.

\section{Immunohistochemistry}

For BrdU and Ki-67 immunohistochemistry, sections were permeabilized ( $15 \mathrm{~min}$ in $1 \%$ Triton $\mathrm{X}-100 / 0.1 \mathrm{M} \mathrm{PBS}$ ), denaturated (30 mins in $2 \mathrm{M} \mathrm{HCl}$ at $37^{\circ} \mathrm{C}$ ), and then neutralized with boric acid (10 mins at RT in $0.1 \mathrm{M} \mathrm{H}_{3} \mathrm{BO}_{3}$ ( $\mathrm{pH}$ 8.5)). Sections were blocked for $1 \mathrm{~h}$ in a blocking solution (3\% Normal Goat Serum, 0.3\% Triton X-100 in $0.1 \mathrm{M}$ PBS at RT) followed by incubation overnight in primary antibody (Rat anti-BrdU, 1:500, Accurate Chemical, Westbury, NY; Rabbit anti-Ki-67, 1:1000, Novocastra, Newcastle upon Tyne, UK). Sections were then incubated $2 \mathrm{~h}$ at RT with an Alexa Fluor immunofluorescent secondary antibody (anti-rat IgG Alexa Fluor-488, 1:500; anti-rabbit IgG Alexa Fluor-568 1:200, Molecular Probes, Invitrogen, Sweden). Sections were finally mounted on Polylysine coated slides (Histolab, Uppsala, Sweden), dried, and coverslipped using VECTASHIELD ${ }^{\circledR}$ HardSet $^{\mathrm{TM}}$ anti-fade mounting medium (Vector Laboratories, Burlingame, CA, USA).

For the DCX and TH immunohistochemistry, staining were visualized using 3,3'-diaminobenzidine (DAB). Sections were permeabilized ( $15 \mathrm{~min}$ in $1 \%$ Triton X-100/ $0.1 \mathrm{M}$ PBS) and blocked against endogenous peroxidases
(20 min with $3 \% \mathrm{H}_{2} \mathrm{O}_{2} / 0.1 \mathrm{M}$ PBS). Sections were then incubated with blocking solution for $1 \mathrm{~h}$ with serum followed by the primary antibody (guinea pig anti-DCX, 1:500 or rabbit anti-TH, 1:500, Millipore, Sweden; overnight at $4{ }^{\circ} \mathrm{C}$ ) and the secondary biotinylated antibody (goat anti-guinea pig $\operatorname{IgG}$ or goat anti-rabbit, 1:200, Vector Laboratories, Burlingame, $\mathrm{CA} ; 2 \mathrm{~h}$ at room temperature). A signal amplification step was then performed by incubation in $\mathrm{ABC}$ reagent (ABC kit Vector Laboratories, Burlingame, $\mathrm{CA}$; for $1 \mathrm{~h}$ ) followed by a reaction with $0.05 \%$ DAB-tetrahydrochloride $/ 0.01 \%$ hydrogen peroxide in phosphate buffer. Finally, sections were dehydrated and mounted on Polylysine coated slides (Histolab), dried, and coverslipped using VECTASHIELD ${ }^{\circledR}$ HardSet $^{\mathrm{TM}}$ anti-fade mounting medium (Vector Laboratories).

Flourescent or DAB images were captured using a Nikon Eclipse E600 light microscope connected to a Nikon digital sight DS-U1 camera using the NIS-Elements F 2.20 software.

BrdU, Ki-67, DCX, and TH quantification procedure

In these experiments, we used an established variation of design-based sterology to quantify cell proliferation (Malberg et al. 2000) to investigate sections from the entire structure in question (SVZ or SGZ). This method differs from true sterology as it is an estimation of the number of cells in the entire structure and not an actual sample of cells/volume. In brief, every eighth section throughout the hippocampus or SVZ was processed for BrdU, Ki-67, and DCX immunohistochemistry resulting in each section being $320 \mu \mathrm{m}$ apart, thus ensuring that the same cell would only be counted once. The number of BrdU, Ki-67, and DCX labeled cells revealed by immunofluorescence or DAB staining was then visualized using a fluorescent microscope. Quantification in the SGZ was done using $40 \times$ magnification by an investigator blind to treatment history who manually counted the fluorescently labeled $\mathrm{BrdU}$ and $\mathrm{Ki}-67$ cells in the granular cell layer (GCL) and the SGZ, which is defined as a two-cell soma-wide zone along the base of the GCL. Cells were considered BrdU, Ki-67, or DCX positive when having nuclei filled with immunofluorescence or DAB and groups of clustered cells were counted as one cell. To estimate the total number of cells in the entire dentate gyrus, the number of positive cells was therefore multiplied by 8 as only every eighth section was counted. For quantification in the SVZ, an investigator blind to treatment history recorded several images at 20× magnification along the entire SVZ for each section using image software. The images were then stitched together using Photoshop (Adobe Photoshop CS), and the resulting high definition image was then analyzed using image analysis software (Image J, NIH, Bethesda, USA). Briefly, the image was converted to an 8-bit black and white 
image which was then filtered using a preset threshold of 120. Adjoining BrdU staining cells were separated using the watershed function and finally, BrdU positive cells around or above the size of a nucleus were quantified using the analyze particles function. This image analysis method was verified using a manual counting procedure which gave comparable values. The numbers of positive cells were again multiplied by 8 to give an estimation of the total number of cells in the SVZ.

Sections which had undergone DAB staining of TH were digitized using a Dia-Scanner (Epson Perfection 4870 PHOTO). Optical density values were measured using Scion Image for Windows (alfa 4.0.3.2; (C) 2000-2001 Scion Corporation).

\section{Autoradiographic detection of DAT}

Slide mounted sections for detection of DAT were preincubated in $50 \mathrm{mM}$ Tris- $\mathrm{HCl} / 120 \mathrm{mM} \mathrm{NaCl}(\mathrm{pH} 7.5)$ for $20 \mathrm{~min}$. Incubation in binding buffer $(50 \mathrm{mM}$ Tris- $\mathrm{HCl} /$ $120 \mathrm{mM} \mathrm{NaCl}, \mathrm{pH} 7.5 / 1 \mu \mathrm{M}$ fluoxetine) was conducted with $50 \mathrm{pM}\left[{ }^{125} \mathrm{I}\right]$ RTI-55 (Perkin-Elmer Life Sciences, Boston, USA) for $60 \mathrm{~min}$. For nonspecific binding, $100 \mu \mathrm{M}$ nomifensine was added to the assay. The slides were washed $2 \times 10 \mathrm{~s}$ in ice-cold binding buffer, rapidly dipped in deionized water, dried, and exposed to autoradiographic films in X-ray cassettes at $-20^{\circ} \mathrm{C}$ for $2-7$ days for $\left[{ }^{125} \mathrm{I}\right]$ (BioMax MR, Merck Eurolab, Sweden). The films were manually developed (Kodak D19, Unifix). Autoradiograms were digitized using a Dia-Scanner (Epson Perfection 4870 PHOTO), and optical density values were measured using Scion Image for Windows (alfa 4.0.3.2; (C) 2000-2001 Scion Corporation).

\section{Statistical analysis}

Efficacy of the unilateral 6-OHDA lesioning was analyzed using student $t$ test. AIMs were analyzed with the nonparametric Kruskal-Wallis test followed by Dunn's Multiple Comparison Test. All the other behavioral tests and immunohistochemical data on cell proliferation and neurogenesis were analyzed using two-way analysis of variance (ANOVA) followed by Bonferroni's test for pairwise comparisons.

\section{Results}

Efficacy of the unilateral 6-OHDA lesioning

The efficacy of the unilateral 6-OHDA lesioning in all studied rats, both from the acute and chronic experiments, was evaluated by apomorphine-induced rotations (see above). In addition, in animals from the chronic experiment, post-mortem analysis of the efficacy of the unilateral 6-OHDA lesioning was evaluated by DAB staining of TH as well as $\left[{ }^{125} \mathrm{I}\right]$ RTI-55 binding to DAT. As shown in Fig. 1, the 6-OHDA lesioning caused a highly significant
Fig. 1 Effects of unilateral 6OHDA lesioning on tyrosine hydroxylase $(\mathrm{TH})$ and dopamine transporter (DAT) levels in rats $(n=23)$. a, b Upper panels show the DAB staining of TH and ${ }^{125}$ I]RTI-55 autoradiographic binding of DAT in the striatum in a unilaterally 6-OHDAlesioned rat. c, d Lower panels show histograms of the quantification of the efficacy of 6-OHDA lesioning in terms of reduction of TH and DAT. $* * * p<0.001$ vs. intact; Student's $t$ test a

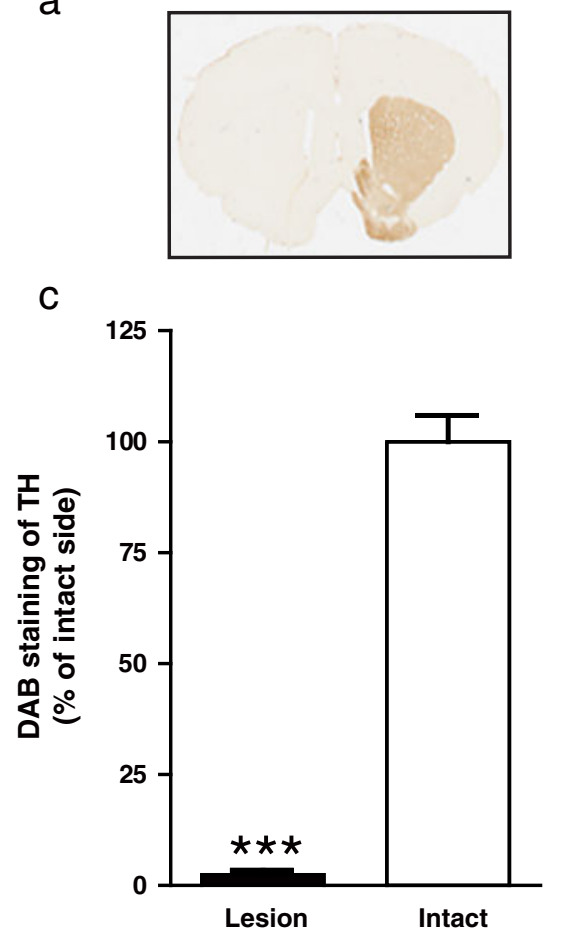

b

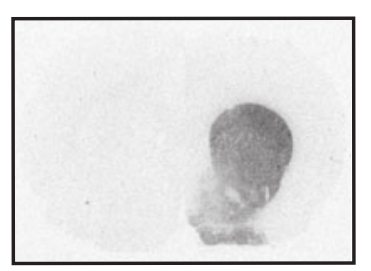

d

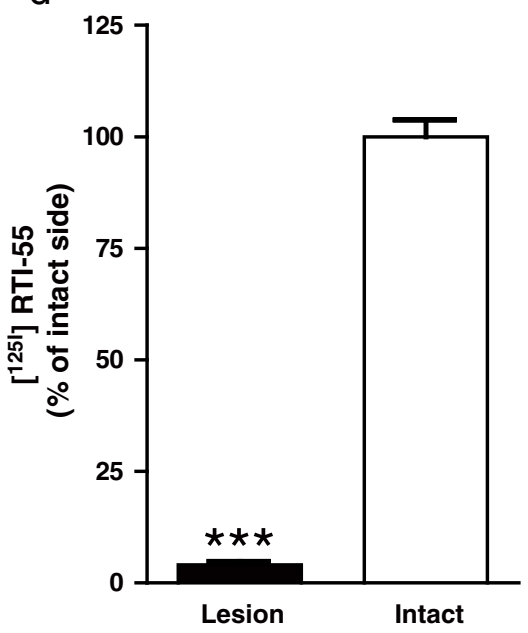


and near-complete reduction of TH $(t=16.36$ and $\mathrm{df}=42$; $p<0.0001)$ and DAT $(t=24.63$ and $\mathrm{df}=22 ; p<0.0001)$ at the level of striatum. There was also a significant reduction $(t=4.85$ and $\mathrm{df}=35 ; p<0.0001)$ of DAT binding at the level of hippocampus $(76.96 \pm 2.874 \%$ of intact side).

Sarizotan reduced immobility in mFST of unilaterally 6-OHDA-lesioned rats

Learned-helplessness models, in which experimental animals are exposed to inescapable aversive situations, e.g., the mFST, are of utility for predicting antidepressant efficacy. During these tests, rats show alternate periods of agitation and immobility (Porsolt et al. 1977; Lucki 1997). It is well established that acute treatment with various antidepressant drugs specifically reduces immobility in these tests without nonspecific increases in motor activity. Two-way ANOVA analysis (treatment $\times$ dopamine level) showed a significant difference for treatment $\left(F_{[2,50]}: 4.0\right.$; $p<0.05)$, but not for the dopamine level $\left(F_{[1,50]}: 2.0 ; p>\right.$ $0.05)$ and their interaction $\left(F_{[2,50]}: 1.3 ; p>0.05\right)$. Subsequent pairwise analysis showed that there was a strong trend for unilaterally 6-OHDA-lesioned rats to be more immobile in the mFST compared to normal rats $(p=0.08)$. The post-hoc analysis showed that both doses of sarizotan ( 1 and $2.5 \mathrm{mg} / \mathrm{kg}$, i.p.) significantly reduced immobility in unilaterally 6-OHDA-lesioned rats, but not in the normal rats (Fig. 2a). This reduction in immobility appeared to be independent of a general increase in motor activity since sarizotan had no effect on horizontal activity (treatment $\left(F_{[2,50]}: 0.32 ; p>0.05\right)$; dopamine level $\left(F_{[1,50]} 0.68 ; p>0.05\right)$, or their interaction $\left.\left(F_{[2,50]}: 1.9 ; p>0.05\right)\right)$ neither in unilaterally 6-OHDA-lesioned nor in normal rats (Fig. 2b).

\section{Effects of sarizotan and L-DOPA/benserazide}

on thigmotaxis and corner time of unilaterally

6-OHDA-lesioned rats

Thigmotaxis, i.e., peripheral activity divided by total horizontal activity and corner time are qualitative measures of motor activity thought to underlie anxiety-like behaviors. Preliminary data indicated no effect of sarizotan alone on these measures, so we decided to study effects of sarizotan alone and in combination with L-DOPA/benserazide. Twoway ANOVA analysis (treatment $\times$ day) showed significant treatment differences both on thigmotaxis (treatment $\left(F_{[3,33]}: 10.9 ; p<0.0001\right)$; but not on day $\left(F_{[1,33]}: 3.34 ; p>\right.$ $0.05)$ or their interaction $\left.\left(F_{[3,33]}: 0.82 ; p>0.05\right)\right)$ and corner time (treatment $\left(F_{[3,33]}: 9.4 ; p<0.0001\right)$; but not on day $\left(F_{[1,33]}: 2.0 ; p>0.05\right)$ or their interaction $\left(F_{[3,33]}: 0.03 ; p>\right.$ $0.05)$ ). As shown in Fig. 3, pairwise analyses demonstrated that chronic treatment with L-DOPA/benserazide signifi- cantly decreased thigmotaxis and corner time compared to animals treated with saline or sarizotan. Sarizotan alone had

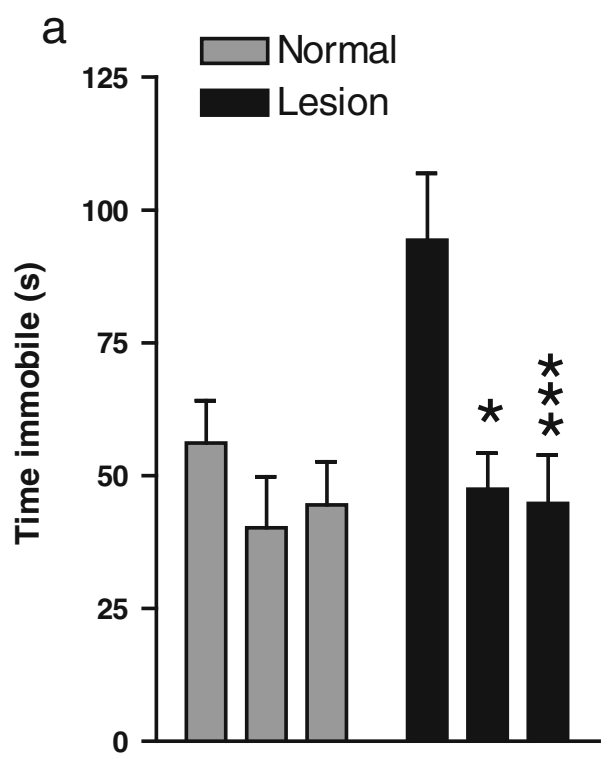

b

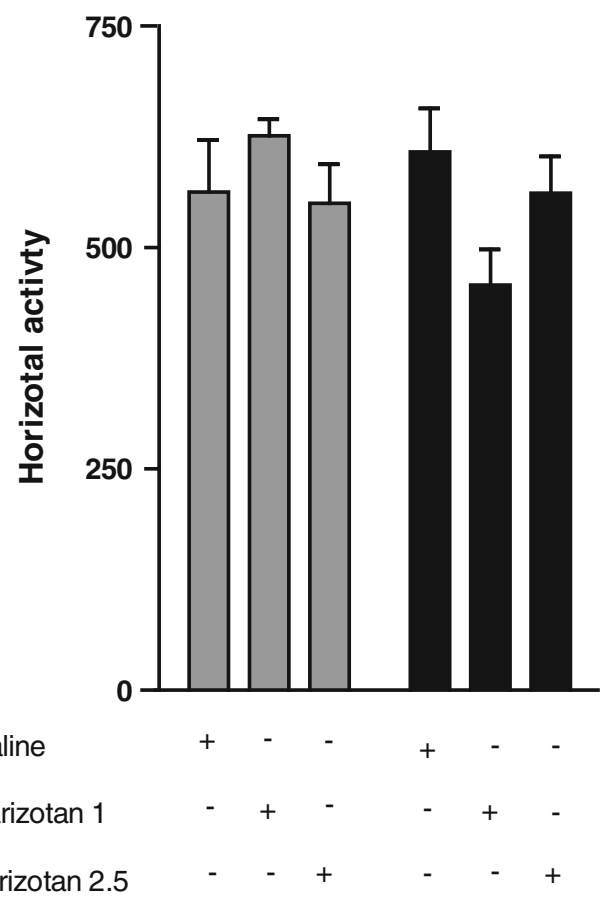

Fig. 2 Acute treatment with sarizotan reduces immobility in the modified forced swim test (mFST) of unilaterally 6-OHDA-lesioned but not in the normal rats. a The effect of saline and sarizotan on immobility in the $\mathrm{mFST}$ in normal (saline $n=6$; sarizotan $1 \mathrm{mg} / \mathrm{kg} n=6$; sarizotan $2.5 \mathrm{mg} / \mathrm{kg} n=6$ ) and unilaterally 6-OHDA-lesioned (saline $n=15$; sarizotan $1 \mathrm{mg} / \mathrm{kg} n=6$; sarizotan $2.5 \mathrm{mg} / \mathrm{kg} n=16$ ) rats. b The effect of saline and sarizotan on the horizontal activity in the open field of normal and unilaterally 6 -OHDA-lesioned rats. ${ }^{*} p<0.05,{ }^{* * *} p<0.001$ versus saline in the unilaterally 6-OHDA-lesioned rats; two-way ANOVA followed by Bonferroni's test for pairwise comparisons 


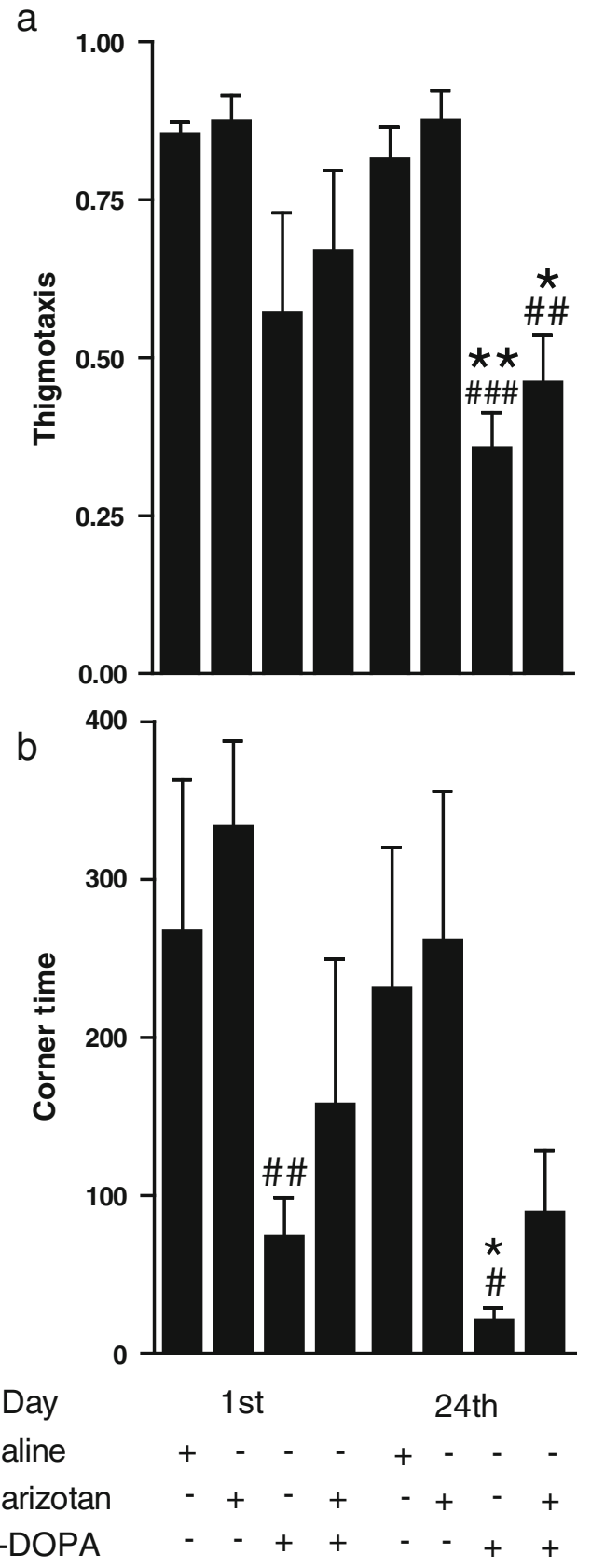

Fig. 3 Effects of acute and chronic treatment with sarizotan and LDOPA/benserazide on thigmotaxis and corner time in unilaterally 6OHDA-lesioned rats. a The effects of saline $(n=4)$, sarizotan $(n=5)$, and L-DOPA/benserazide $(n=9)$ alone or sarizotan + L-DOPA/benserazide in combination $(n=5)$ on thigmotaxis (i.e., peripheral activity divided by total horizontal activity). b The effects of saline, sarizotan, and L-DOPA/benserazide alone or sarizotan $+\mathrm{L}-\mathrm{DOPA} /$ benserazide in combination on corner time. ${ }^{*} p<0.05,{ }^{*} p<0.01$ versus saline from the same day; $\# p<0.05, \# \# p<0.01, \# \# \# p<0.001$ versus sarizotan from the same day. Two-way ANOVA followed by Bonferroni's test for pairwise comparisons

no effects and no differences between L-DOPA/benserazidetreated rats and sarizotan $+\mathrm{L}-\mathrm{DOPA} /$ benserazide-treated rats on these measures could be found.
Effects of sarizotan on L-DOPA/benserazide-induced rotations, AIMs, and motor activity in 6-OHDA-lesioned rats

To confirm that sarizotan, in our experimental setting, has beneficial actions against the development of motoric LDOPA-induced side-effects, we examined whether it could reduce L-DOPA-induced effects on supersensitized rotations, AIMs, and motor activity. Unilaterally 6-OHDAlesioned rats were treated with saline, sarizotan, L-DOPA/ benserazide alone or sarizotan $+\mathrm{L}$-DOPA/benserazide in combination for 24 days. As shown in Fig. 4a, rotational behaviors were measured on days 1 and 24, and a two-way ANOVA analysis (treatment $\times$ day) showed a significant difference for treatment $\left(F_{[3,38]} 14.5 ; p<0.0001\right)$, but not for the day $\left(F_{[1,38]} 2.85 ; p>0.05\right)$. A significant interaction between treatment and day was found $\left(F_{[3,38]} 5.59 ; p<\right.$ 0.01 ). Subsequent pairwise analysis showed that sarizotan alone had no effect on rotations, while for L-DOPA/ benserazide alone, the number of rotations was significantly increased on day 24. Following co-treatment with sarizotan+ L-DOPA/benserazide for 24 days, there were significantly fewer rotations compared to treatment with L-DOPA/ benserazide alone. To better characterize the supersensitive responsivity and possible disadvantageous effects of LDOPA/benserazide and its reversal by sarizotan, we also measured AIMs on day 24. An overall analysis using the non-parametric Kruskal-Wallis test showed significant differences $\left(\chi^{2} 14.23 ; p<0.001\right)$ between the studied groups, and in agreement with previous studies (e.g., Lundblad et al. 2004; Zhang et al. 2008), repeated L-DOPA/benserazide treatment increased AIMs when compared to saline $(p<0.01)$ (Fig. 4b). Moreover, rats co-treated with sarizotan and LDOPA/benserazide showed significantly $(p<0.05)$ lower AIMs scores as compared to rats treated with L-DOPA/ benserazide alone (Fig. 4b). To assess whether the effects of sarizotan on L-DOPA/benserazide-induced hyperactivity was related to a general reduction in motor activity or more specifically involved in lowering AIMs, the motor activity was measured in open-field boxes on days 1 and 24. A twoway ANOVA analysis (treatment $\times$ day) showed significant differences on horizontal activity both for treatment $\left(F_{[3,38]}\right.$ 13.3; $p<0.0001)$ and day $\left(F_{[1,38]} 8.4 ; p<0.01\right)$, but not for interaction $\left(F_{[3,38]} 0.84 ; p>0.05\right)$. Pairwise analysis showed that chronic treatment with either L-DOPA/benserazide or combined sarizotan + L-DOPA/benserazide significantly increased horizontal activity on day 24 when compared to rats treated with saline or sarizotan alone. No difference between L-DOPA/benserazide- and sarizotan $+\mathrm{L}-\mathrm{DOPA} /$ benserazidetreated rats was found (Fig. 4c). There were no significant differences between any of the studied groups on rearing activity (treatment $\left(F_{[3,38]} 0.39 ; p>0.05\right)$; day $\left(F_{[1,38]} 3.6 ; p>\right.$ $0.05)$ or their interaction $\left.\left(F_{[3,38]} 0.26 ; p>0.05\right)\right)$ (Fig. $\left.4 \mathrm{~d}\right)$. 
Fig. 4 Effects of acute and chronic treatment with sarizotan on L-DOPA/benserazide-induced rotations, abnormal involuntary movements (AIMs) and motor activity in unilaterally 6-OHDAlesioned rats. a, b, c, $\mathbf{d}$ The effect of saline $(n=4)$, sarizotan $(n=5)$, and L-DOPA/benserazide $(n=9)$ alone or sarizotan + L-DOPA/benserazide in combination $(n=5)$ on contralateral rotations (a), AIMs (b), horizontal activity (c), and rearing activity (d) in unilaterally 6-OHDA-lesioned rat on days 1 and $24 .{ }^{*} p<0.05, * * p<0.01$, $* * * p<0.001$ versus saline from the same day; $\# \# p<0.01$ versus sarizotan from the same day; $+p<0.05,+++p<0.001$ versus sarizotan $+\mathrm{L}-\mathrm{DOPA} /$ benserazide from the same day; $\S p<0.05$, $\S \S \S p<0.001$ versus L-DOPA on day 1. Two-way ANOVA followed by Bonferroni's test for pairwise comparisons. AIMs were analyzed with nonparametric Kruskal-Wallis test followed by Dunn's multiple comparison test a

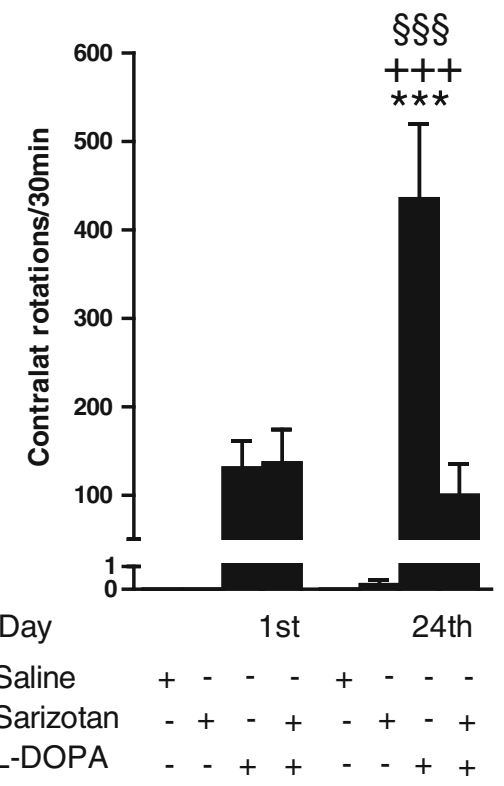

C

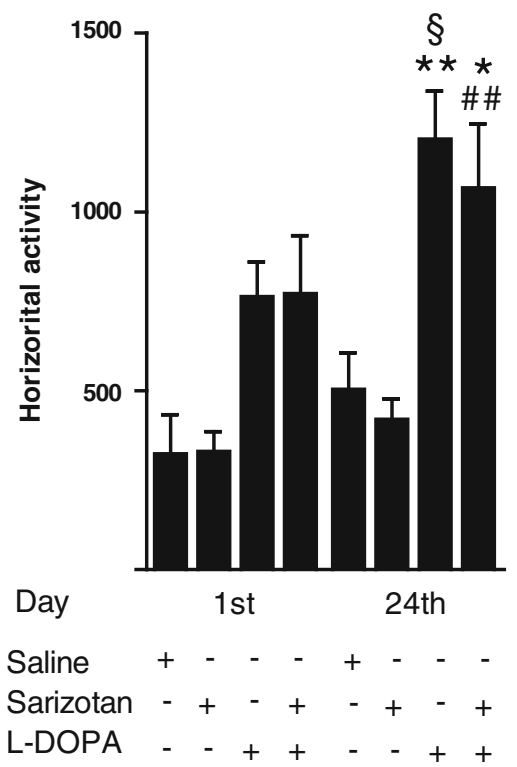

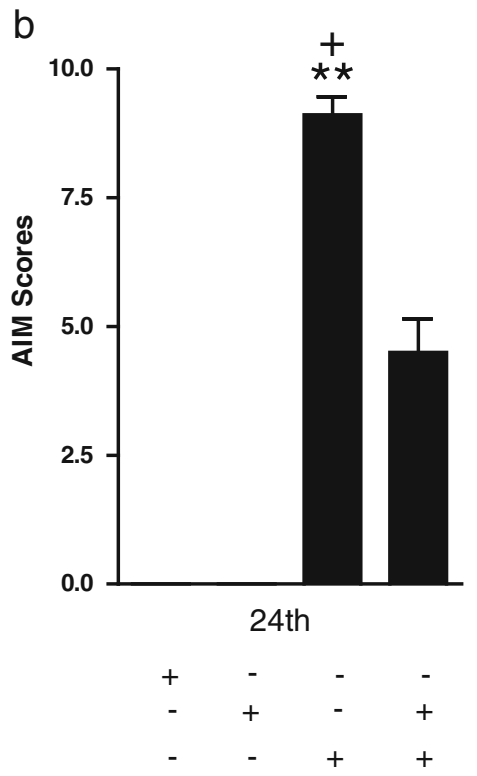

d

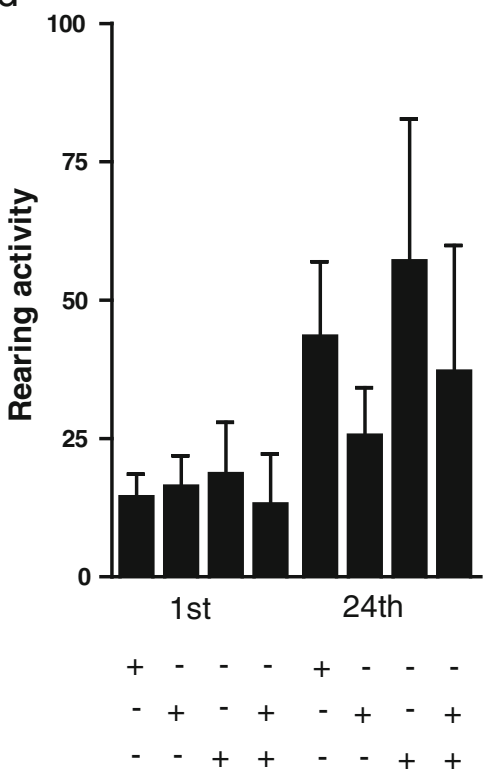

Sarizotan increases cell proliferation in the SVZ in a 6-OHDA-lesioned hemisphere

To further examine whether sarizotan may have antidepressant-like properties, histological measures of cell proliferation, known to be regulated by antidepressants, were studied. Unilaterally 6-OHDA-lesioned rats were subchronically treated with saline, sarizotan, or L-DOPA/ benserazide alone or sarizotan $+\mathrm{L}-\mathrm{DOPA} /$ benserazide in combination for 24 days. To examine cell proliferation using the incorporation of $\mathrm{BrdU}$, rats were treated with multiple BrdU injections $(4 \times 50 \mathrm{mg} / \mathrm{kg}$ every $2 \mathrm{~h})$ on the 23rd day and sacrificed $24 \mathrm{~h}$ after the last BrdU injection. Subsequently, immunohistochemical visualization of incor- porated BrdU staining cells was made in the SVZ (Fig. 5). Two-way ANOVA analysis (treatment $\times$ dopamine level) showed a significant difference for treatment $\left(F_{[3,34]} 5.7\right.$; $p<0.01)$, but not for the dopamine level $\left(F_{[1,34]} 0.38 ; p>\right.$ $0.05)$ or their interaction $\left(F_{[3,34]} 0.38 ; p>0.05\right)$. Pairwise analyses showed that treatment with sarizotan or L-DOPA/ benserazide alone or sarizotan $+\mathrm{L}-\mathrm{DOPA} /$ benserazide in combination significantly increased cell proliferation in the 6-OHDA-lesioned side. No significant effect of these treatments was found in the intact hemisphere.

It was unfortunately impossible to distinguish individual DCX positive cells in the SVZ as they were densely packed and no reliable quantification could be performed (data not shown). 
a

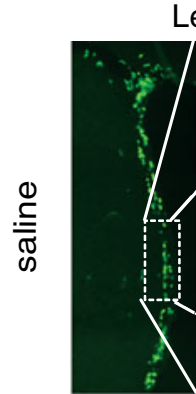

Lesion
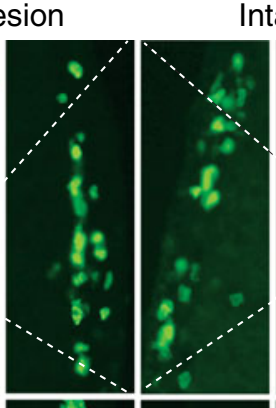

ntact
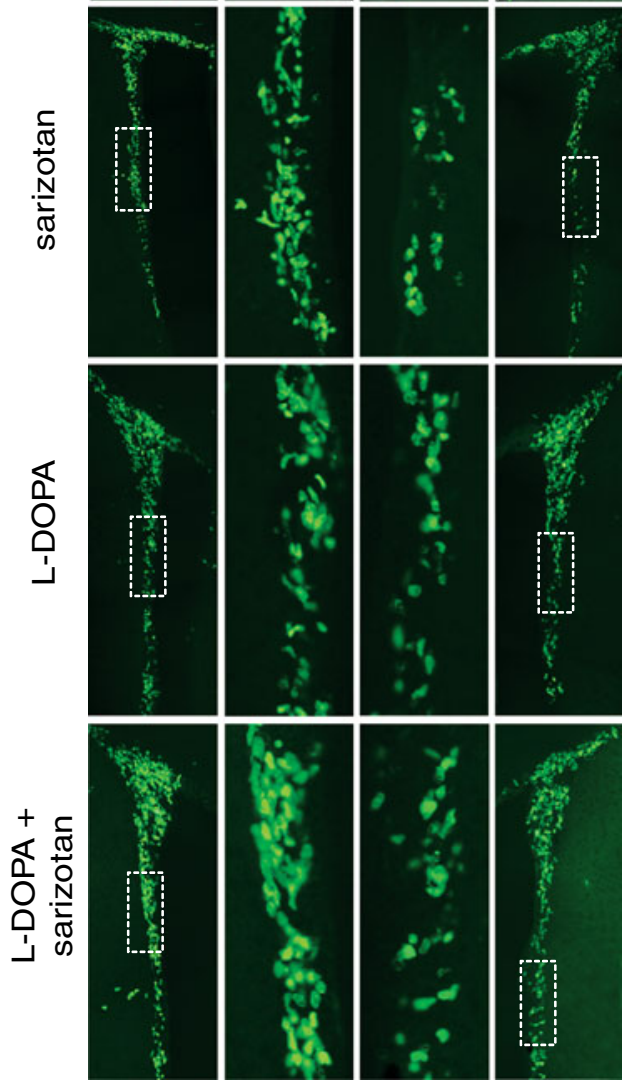

b

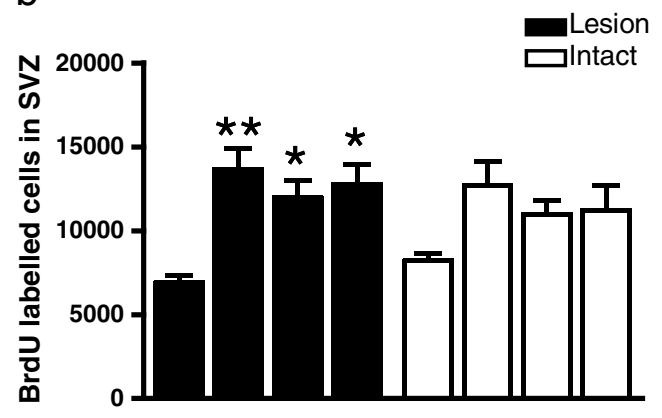

Saline $\begin{array}{lllllllll}\text { Saline } & + & - & - & - & + & - & - & - \\ \text { Sarizotan } & - & + & - & + & - & + & - & + \\ \text { L-DOPA } & - & - & + & + & - & - & + & +\end{array}$
Fig. 5 Chronic treatment with sarizotan increases cell proliferation in the SVZ of the striatum. a Representative images show differences in numbers of BrdU cells in the SVZ of the striatum after treatment with saline $(n=4)$, sarizotan $(n=5)$, or L-DOPA/benserazide $(n=9)$ alone or sarizotan + L-DOPA/benserazide in combination $(n=5)$ in both the lesioned and intact sides both in low magnification and high magnification (inserts). b Quantification of BrdU positive cells in the SVZ revealed significant increases in cell proliferation on the 6OHDA-lesioned side with sarizotan and L-DOPA/benserazide both alone or in combination. ${ }^{*} p<0.05,{ }^{*} p<0.01$ versus saline lesioned side; two-way ANOVA followed by Bonferroni's test for pairwise comparisons

Sarizotan increases cell proliferation and neurogenesis in the SGZ of the dentate gyrus of hippocampus in a 6-OHDA-lesioned hemisphere

In the hippocampus, adult neurogenesis occurs in the granular zone of the dentate gyrus, beginning with cell proliferation in the SGZ. The experiment was designed to examine both cell proliferation (measured by BrdU and Ki67) and neurogenesis (measured by DCX) in this region. In studies of BrdU incorporation, a two-way ANOVA analysis (treatment $\times$ dopamine level) showed a significant difference for treatment $\left(F_{[3,36]} 7.4 ; p<0.01\right)$, but not for the dopamine level $\left(F_{[1,36]} 1.4 ; p>0.05\right)$ or their interaction $\left(F_{[3,36]} 1.3\right.$; $p>0.05)$. Subsequent pairwise comparisons revealed that treatment with sarizotan alone or in combination with LDOPA/benserazide significantly increased BrdU incorporation in the 6-OHDA-lesioned side in comparison to saline as well as L-DOPA/benserazide alone (Fig. 6a, b). No significant effect of the treatments was found in the intact hemisphere.

Cell proliferation in the SGZ was also examined using immunohistochemical visualization of the mitotic marker Ki-67 (Scholzen and Gerdes 2000). Two-way ANOVA analysis (treatment $\times$ dopamine level) showed a significant difference on Ki-67 staining for treatment $\left(F_{[3,38]} 5.9 ; p<\right.$ $0.01)$ and for the dopamine level $\left(F_{[1,38]} 12.2 ; p<0.01\right)$, but not for their interaction $\left(F_{[3,38} 2.4 ; p>0.05\right)$. Pairwise comparisons of the results from the Ki-67 staining revealed that sarizotan and L-DOPA/benserazide alone or sarizotan+ L-DOPA/benserazide in combination significantly increased cell proliferation in the 6-OHDA-lesioned side in the SGZ in comparison to saline (Fig. 7a, b). There was also a significant difference between the 6-OHDA-lesioned side and the intact side in response to treatment with sarizotan and L-DOPA/benserazide (Fig. 7b). Furthermore, in the intact side, a significant difference between animals treated with L-DOPA and sarizotan+L-DOPA/benserazide was found.

To examine neurogenesis in the SGZ, measurements of DCX were made. Two-way ANOVA analysis (treatment $\times$ dopamine level) showed a significant differ- 
Fig. 6 Chronic treatment with sarizotan increases cell proliferation in the SGZ of the dentate gyrus. a Representative images show differences in numbers of BrdU positive cells in the SGZ of the hippocampus after treatment with saline $(n=4)$, sarizotan $(n=5)$, or L-DOPA/benserazide $(n=9)$ alone or sarizotan $+\mathrm{L}-\mathrm{DO}$ $\mathrm{PA} /$ benserazide in combination $(n=5)$ in both the lesioned and intact sides. b Quantification of BrdU positive cells in the SGZ revealed a significant increase in cell proliferation on the 6OHDA-lesioned side with sarizotan alone or in combination with L-DOPA/benserazide. ${ }^{*} p<0.05,{ }^{*} p<0.01$ versus saline in the lesioned side; ${ }^{\#} p<0.01$ versus L-DOPA/benserazide in the lesion side; two-way ANOVA followed by Bonferroni's test for pairwise comparisons
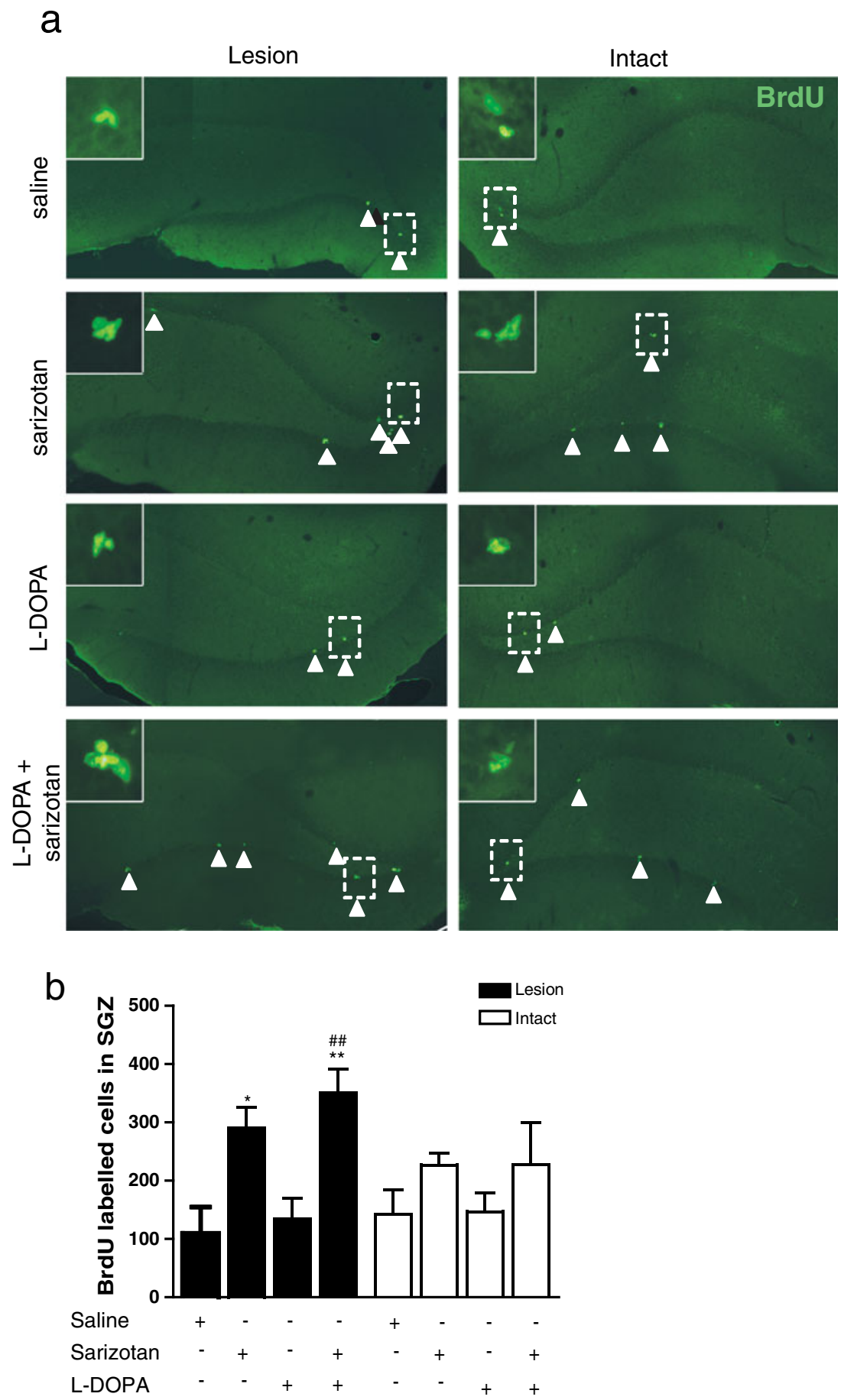

ence for DCX staining for treatment $\left(F_{[3,36]} 2.9 ; p<\right.$ $0.05)$, but not for the dopamine level $\left(F_{[1,36]} 1.6 ; p>0.05\right)$ or their interaction $\left(\mathrm{F}_{[3,36]} 1.2 ; p>0.05\right)$. Pairwise comparisons showed that neither sarizotan nor L-DOPA/ benserazide had any significant actions by themselves, but their combination increased DCX levels in the 6OHDA-lesioned side compared to saline and L-DOPA/ benserazide alone (Fig. 8a, b). No significant effect of any of the studied treatments was found in the intact hemisphere. 
a
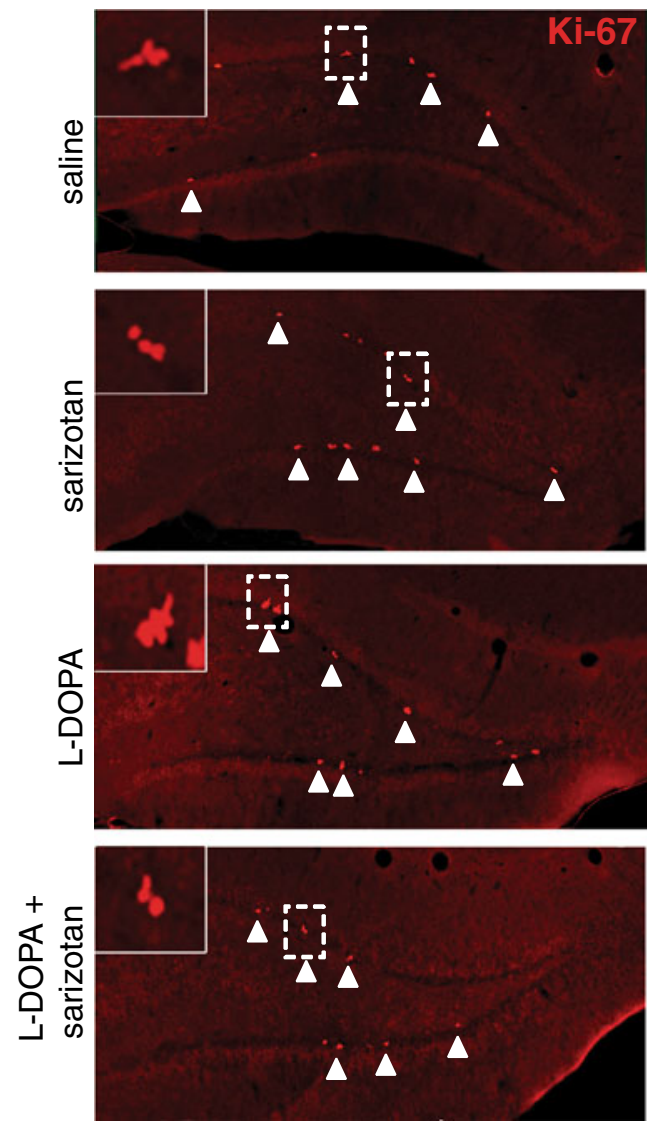

b

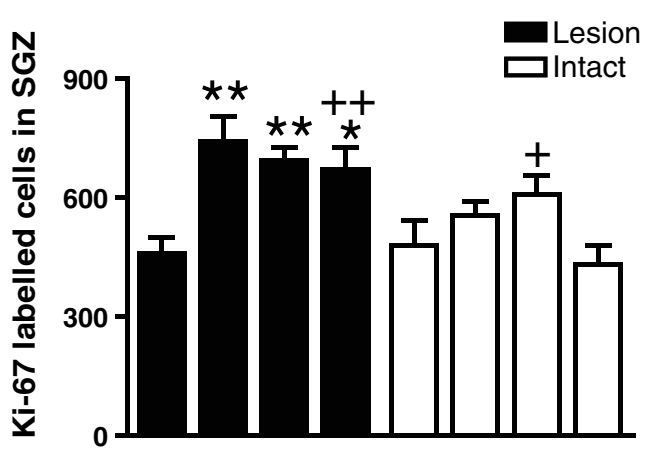

$\begin{array}{lllllllll}\text { Saline } & + & - & - & - & + & - & - & - \\ \text { Sarizotan - } & + & - & + & - & + & - & + \\ \text { L-DOPA } & - & - & + & + & - & - & + & +\end{array}$

\section{Discussion}

The major findings of this study are that sarizotan has antidepressant-like activity in a behavioral and in a histological measure. In unilaterally 6-OHDA-lesioned rats, sarizotan significantly reduces immobility in the modified forced swim test. Moreover, sarizotan stimulates cell proliferation in both the SGZ and SVZ in the 6-OHDAlesioned hemisphere.
Fig. 7 Chronic treatment with sarizotan increases cell proliferation in the SGZ of the dentate gyrus. a Representative images show differences in numbers of Ki-67 positive cells in the SGZ of the hippocampus after treatment with saline $(n=4)$, sarizotan $(n=5)$, or LDOPA/benserazide $(n=9)$ alone or sarizotan+L-DOPA/benserazide in combination $(n=5)$ in the lesioned sides. b Quantification of Ki-67 positive cells in the SGZ revealed significant increases in cell proliferation in the 6-OHDA-lesioned side with either sarizotan or LDOPA/benserazide alone or their combination. ${ }^{*} p<0.05, * * p<0.01$ versus saline in the lesioned side; $+p<0.05 ;++p<0.01$ versus sarizotan + L-DOPA/benserazide in the intact side; two-way ANOVA followed by Bonferroni's test for pairwise comparisons

One third of the patients suffering from PD exhibit clinically significant depressive symptoms which contribute to severe disability, impaired quality of life, and shortened life expectancy (Chaudhuri et al. 2006; Reijnders et al. 2008). There is a lack of established evidence-based treatments against depression in PD and a complication is that resting tremor is worsened by SSRIs in many PD patients (Chaudhuri et al. 2006). Moreover, it actually appears that the biochemical responsivity towards SSRIs differ between PD patients with co-morbid depression and patients with only depression (Pålhagen et al. 2010). It is therefore of clinical importance to find novel compounds for the treatment of depression and anxiety in PD.

In the present study, we hypothesized that sarizotan may have antidepressant properties. To address this question, we studied effects of sarizotan in the mFST, an acute test of an inescapable aversive situation, with predictive validity to assess antidepressant efficacy (Lucki 1997). Using the mFST procedure, there was a strong tendency for the 6-OHDA-lesioned rats to be more immobile ("depressionlike") than normal rats. Interestingly, sarizotan significantly reduced the immobility of unilaterally 6-OHDA-lesioned rats. This antidepressant-like effect of sarizotan cannot simply be explained by a general motor activation since the same concentration of sarizotan did not have any effect on horizontal activity in the open field. Sarizotan also tended to cause an antidepressant-like action in the mFST of normal rats. To further establish antidepressant properties of sarizotan, it would be important to study its actions in additional animal paradigms for antidepressant-like efficacy, like the novelty suppressed feeding test (Santarelli et al. 2003). However, bilateral 6-OHDA-lesioned rats or other symmetric models of Parkinsonism are better suited than unilaterally 6-OHDA-lesioned rats for analysis in this test.

It is known that $5-\mathrm{HT}_{1 \mathrm{~A}}$ receptors regulate anxiety-like behaviors and the partial $5-\mathrm{HT}_{1 \mathrm{~A}}$ receptor agonist buspirone is clinically used as an anxiolytic agent. Based on its affinity towards $5-\mathrm{HT}_{1 \mathrm{~A}}$ receptors, sarizotan could regulate anxiety-like behaviors. However, we could not find any effects of sarizotan on thigmotaxis or corner time in the open field. These data are in agreement with a previous study showing that sarizotan had no effect on marble 
a
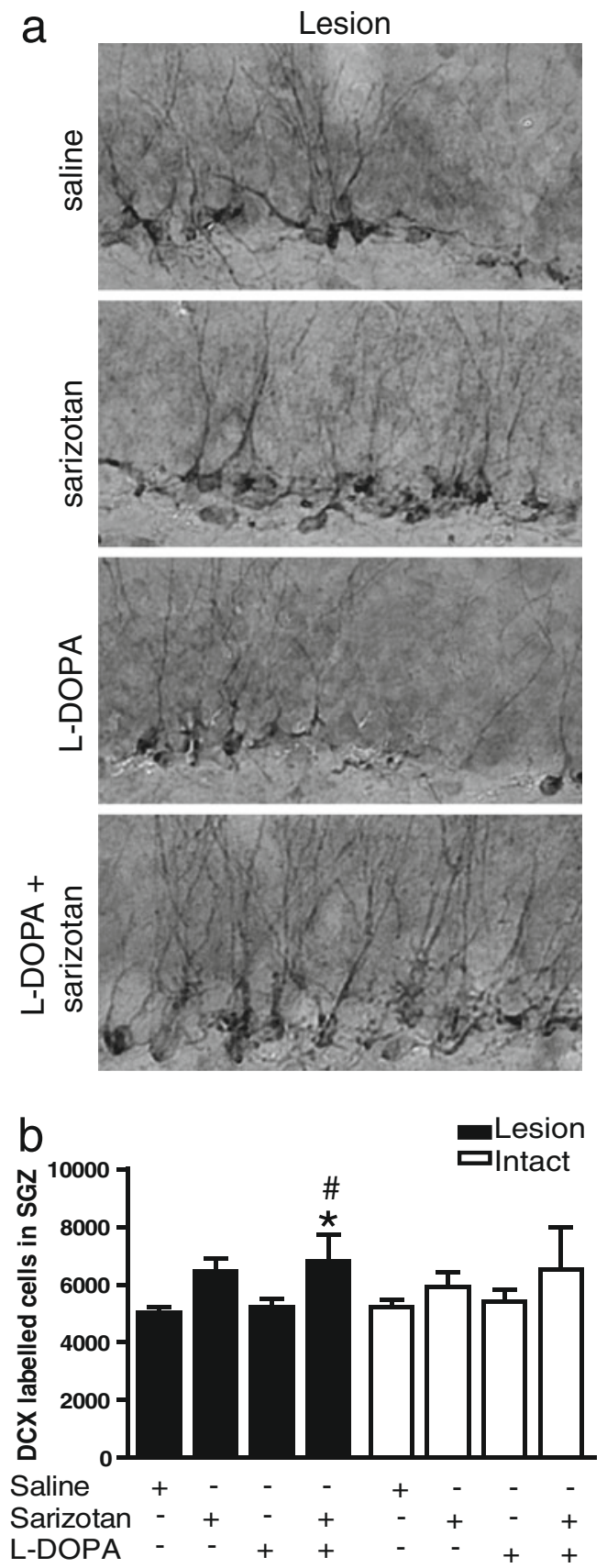

Fig. 8 Chronic treatment with sarizotan increases neurogenesis in the SGZ of the hippocampus. a Representative images from the granular layer of the hippocampus showing differences in numbers of DCX positive cells after treatment with saline $(n=4)$, sarizotan $(n=5)$, or LDOPA/benserazide $(n=9)$ alone or sarizotan+L-DOPA/benserazide in combination $(n=5)$ in the lesioned side. b Quantification of DCX positive cells in the granular layer revealed significant increases in neurogenesis after treatment with sarizotan + L-DOPA/benserazide in combination. ${ }^{*} p<0.05$ versus saline in the lesioned side; $\# p<0.05$ versus L-DOPA/benserazide in the lesioned side; two-way ANOVA followed by Bonferroni's test

burying behavior in mice, another putative preclinical test for anxiety (Bruins et al. 2008). Future experiments may evaluate the effects of sarizotan in other tests of anxiety, such as the elevated plus maze and dark-light box. Somewhat surprisingly, treatment with L-DOPA/benserazide reduced thigmotaxis and corner time. This effect of LDOPA/benserazide cannot be explained by changes in rearing activity, often reflecting stereotypies, but may be biased by L-DOPA/benserazide-induced dyskinetic and rotational behaviors making it more secure for the rat to stay in the center of the arena. In any case, to our knowledge, such effects of L-DOPA/benserazide are not well-characterized and could indicate anxiolytic properties of L-DOPA/benserazide in hemiparkinsonian rats. It should also be noted that PCP-treated rats exhibit a reduced thigmotaxis (Ericson et al. 1991), indicating that certain psychotomimetic responses may lead to reduced thigmotaxis. The functional importance underlying the reduced thigmotaxis by L-DOPA/benserazide needs to be determined in follow-up experiments. Sarizotan did not significantly counteract this action of L-DOPA/benserazide.

Our behavioral data are also in agreement with the previous studies showing that sarizotan, at $2.5 \mathrm{mg} / \mathrm{kg}$, exhibited antidyskinetic actions without any effects on locomotor response to L-DOPA/benserazide in experimental Parkinsonian rats (Bibbiani et al. 2001; Gerlach et al. 2011). Bibbiani and co-workers suggested that this effect of sarizotan could be due to the inhibitory action of 5- $\mathrm{HT}_{1 \mathrm{~A}}$ autoreceptors in regulating the release of dopamine formed as a false neurotransmitter from exogenous L-DOPA in serotonin neurons. Indeed, co-treatment with a $5-\mathrm{HT}_{1 \mathrm{~A}}$ receptor antagonist inhibits the antidyskinetic and sensitizing effects of sarizotan (Bibbiani et al. 2001; Gerlach et al. 2011). In addition, some specific effects of sarizotan on locomotive dyskinesia and dystonia are counteracted by $\mathrm{D}_{3}$ receptor agonism (Gerlach et al. 2011). Initial proof-ofconcept trials actually demonstrated an antidyskinetic effect in patients suffering from PD (Bara-Jimenez et al. 2005), but this effect could not be replicated in a larger follow-up trial (Goetz et al. 2007). However, a subpopulation of PD patients may benefit from sarizotan treatment. Indeed, our data indicate that advanced PD patients with co-morbid depression could benefit from sarizotan to prevent the development of severe dyskinesias and counteract symptoms of depression.

To further study antidepressant-like properties of sarizotan, we performed histological studies of its effects on cell proliferation and neurogenesis. Indeed, it has been shown that chronic, but not acute, treatment with distinct antidepressants increases cell proliferation and neurogenesis in the SGZ in the dentate gyrus of the hippocampus (Malberg et al. 2000). As mentioned above, the stimulatory effects of antidepressants on cell proliferation involves activation of 5- $\mathrm{HT}_{1 \mathrm{~A}}$ receptors (Banasr et al. 2004; Radley and Jacobs 2002; Santarelli et al. 2003). Because of the high affinity of sarizotan at $5-\mathrm{HT}_{1 \mathrm{~A}}$ receptors, the antidepressant-like 
actions of sarizotan in the mFST and the lack of knowledge of serotonergic influence on cell proliferation/neurogenesis in parkinsonian models, we studied effects of sarizotan on various aspects of cell proliferation/neurogenesis in unilaterally 6-OHDA-lesioned rats. An interesting observation throughout this histological study was that sarizotan had more potent effects in the regulation of cell proliferation/ neurogenesis in the 6-OHDA-lesioned hemisphere than in the intact hemisphere. Measurements of BrdU incorporation or endogenous $\mathrm{Ki}-67$ staining were used to study cell proliferation and revealed that treatment with sarizotan alone or in combination with L-DOPA/benserazide increased cell proliferation in the SGZ of the hippocampus in the 6-OHDA-lesioned hemisphere. The number of BrdU positive cells was proportionately smaller to $\mathrm{Ki}-67$. It is therefore likely that the injected BrdU did not label the entire population of dividing cells. However, other unknown factors may also underlie this discrepancy, especially since L-DOPA/benserazide only increased cell proliferation when measured with Ki-67. Whereas sarizotan alone had effects in both assays of cell proliferation in the SGZ, this was only manifested as a trend for an increase in neurogenesis, as measured by the immature neuronal marker DCX. This is not contradictory considering that DCX is a measure of later stages of the neurogenic process and not necessarily directly proportionate to cell proliferation. Neurogenesis was significantly increased in the SGZ by sarizotan when it was combined with L-DOPA/benserazide. Thus, overall, these data support proliferating/ neurogenic effects of sarizotan in the SGZ in a 6-OHDAlesioned hemisphere. Based on the literature and the pharmacological profile of sarizotan, it is likely that 5$\mathrm{HT}_{1 \mathrm{~A}}$ receptors have a significant role in these histological actions of sarizotan in the SGZ. However, to definitively conclude that sarizotan exerts stimulatory effects on cell proliferation and neurogenesis via stimulation of $5-\mathrm{HT}_{1 \mathrm{~A}}$ receptors, it would be necessary to perform experiments in which selective 5- $\mathrm{HT}_{1 \mathrm{~A}}$ receptors antagonists and/or 5$\mathrm{HT}_{1 \mathrm{~A}}$ receptors knockout mice are used to modify the actions of sarizotan.

It was also found that sarizotan increased cell proliferation in the SVZ at the level of striatum. In agreement with previous work (e.g., Hoglinger et al. 2004), L-DOPA/ benserazide also increased cell proliferation in this neurogenic niche. No additive effect of sarizotan and L-DOPA was found. Sarizotan has affinity for dopamine $D_{2}$-like receptors which are present in the SVZ and appears to regulate cell proliferation in this region (Kippin et al. 2005; Newton and Duman 2007), not least in Parkinsonism (Hoglinger et al. 2004; Yang et al. 2008). $\mathrm{D}_{2}$-like receptors could be important in mediating effects of sarizotan on cell proliferation in the SVZ. Indeed, as pointed out by Bartoszyk et al. (2004), sarizotan has some intrinsic dopaminergic activity, as higher doses induce contralateral rotational behavior in unilaterally 6-OHDA-lesioned rats. Moreover, recent data (Gerlach et al. 2011) have implicated $\mathrm{D}_{3}$ receptors in mediating some antidyskinetic and antidystonic responses of sarizotan. It would be informative to study whether $D_{3}$ receptor ligands and/or $D_{3} K O$ mice modulate effects of sarizotan on cell proliferation, particularly in the SVZ.

In conclusion, the behavioral and neurogenic effects of sarizotan are reminiscent to the actions of several antidepressant agents (Malberg et al. 2000; Sahay and Hen 2007). These data suggest that compounds with a pharmacological profile of sarizotan could not only be useful for the treatment of L-DOPA-induced dyskinesias, but could also positively influence non-motor symptoms, such as depression and neurorestorative mechanisms in Parkinsonism.

Acknowledgements The authors declare that they have no conflict of interest. This work was supported by Parkinsonfonden, Vetenskapsrådet, Torsten and Ragnar Söderberg's stiftelse, Hjärnfonden. We would like to thank Dr Gerd Bartoszyk, Merck KGA, for the generous gift of sarizotan.

Open Access This article is distributed under the terms of the Creative Commons Attribution Noncommercial License which permits any noncommercial use, distribution, and reproduction in any medium, provided the original author(s) and source are credited.

\section{References}

Banasr M, Hery M, Printemps R, Daszuta A (2004) Serotonin-induced increases in adult cell proliferation and neurogenesis are mediated through different and common 5-HT receptor subtypes in the dentate gyrus and the subventricular zone. Neuropsychopharmacology 29:450-460

Bara-Jimenez W, Bibbiani F, Morris MJ, Dimitrova T, Sherzai A, Mouradian MM, Chase TN (2005) Effects of serotonin 5-HT1A agonist in advanced Parkinson's disease. Mov Disord 20:932 936

Bartoszyk GD, Van Amsterdam C, Greiner HE, Rautenberg W, Russ H, Seyfried CA (2004) Sarizotan, a serotonin 5-HT1A receptor agonist and dopamine receptor ligand. 1. Neurochemical profile. J Neural Transm 111:113-126

Bibbiani F, Oh JD, Chase TN (2001) Serotonin 5-HT1A agonist improves motor complications in rodent and primate parkinsonian models. Neurology 57:1829-1834

Bruins Slot LA, Bardin L, Auclair AL, Depoortere R, NewmanTancredi A (2008) Effects of antipsychotics and reference monoaminergic ligands on marble burying behavior in mice. Behav Pharmacol 19:145-152

Chaudhuri KR, Healy DG, Schapira AH (2006) Non-motor symptoms of Parkinson's disease: diagnosis and management. Lancet Neurol 5:235-245

Ericson E, Samuelsson J, Ahlenius S (1991) Photocell measurements of rat motor activity. A contribution to sensitivity and variation in behavioral observations. J Pharmacol Methods 25:111-122

Gerlach M, Bartoszyk GD, Riederer P, Dean O, van den Buuse M (2011) Role of dopamine $\mathrm{D}(3)$ and serotonin 5-HT (1A) receptors 
in L-DOPA-induced dyskinesias and effects of sarizotan in the 6hydroxydopamine-lesioned rat model of Parkinson's disease. J Neural Transm. PMID:21253782

Goetz CG, Damier P, Hicking C, Laska E, Muller T, Olanow CW, Rascol O, Russ H (2007) Sarizotan as a treatment for dyskinesias in Parkinson's disease: a double-blind placebo-controlled trial. Mov Disord 22:179-186

Hoglinger GU, Rizk P, Muriel MP, Duyckaerts C, Oertel WH, Caille I, Hirsch EC (2004) Dopamine depletion impairs precursor cell proliferation in Parkinson's disease. Nat Neurosci 7:726-735

Kippin TE, Kapur S, van der Kooy D (2005) Dopamine specifically inhibits forebrain neural stem cell proliferation, suggesting a novel effect of antipsychotic drugs. J Neurosci 25:5815-5823

Lucki I (1997) The forced swimming test as a model for core and component behavioral effects of antidepressant drugs. Behav Pharmacol 8:523-532

Lundblad M, Picconi B, Lindgren H, Cenci MA (2004) A model of LDOPA-induced dyskinesia in 6-hydroxydopamine lesioned mice: relation to motor and cellular parameters of nigrostriatal function. Neurobiol Dis 16:110-123

Malberg JE, Eisch AJ, Nestler EJ, Duman RS (2000) Chronic antidepressant treatment increases neurogenesis in adult rat hippocampus. J Neurosci 20:9104-9110

Newton SS, Duman RS (2007) Neurogenic actions of atypical antipsychotic drugs and therapeutic implications. CNS Drugs 21:715-725

Pålhagen S, Qi H, Mårtensson B, Wålinder J, Granérus AK, Svenningsson P (2010) Monoamines, BDNF, IL-6 and corticosterone in CSF in patients with Parkinson's disease and major depression. J Neurol 257:524-532
Porsolt RD, Le Pichon M, Jalfre M (1977) Depression: a new animal model sensitive to antidepressant treatments. Nature 266:730-732

Radley JJ, Jacobs BL (2002) 5-HT1A receptor antagonist administration decreases cell proliferation in the dentate gyrus. Brain Res 955:264-267

Ramboz S, Oosting R, Amara DA, Kung HF, Blier P, Mendelsohn M, Mann JJ, Brunner D, Hen R (1998) Serotonin receptor 1A knockout: an animal model of anxiety-related disorder. Proc Natl Acad Sci USA 95:14476-14481

Reijnders JS, Ehrt U, Weber WE, Aarsland D, Leentjens AF (2008) A systematic review of prevalence studies of depression in Parkinson's disease. Mov Disord 23:183-189, quiz 313

Sahay A, Hen R (2007) Adult hippocampal neurogenesis in depression. Nat Neurosci 10:1110-1115

Santarelli L, Saxe M, Gross C, Surget A, Battaglia F, Dulawa S, Weisstaub N, Lee J, Duman R, Arancio O, Belzung C, Hen R (2003) Requirement of hippocampal neurogenesis for the behavioral effects of antidepressants. Science 301:805-809

Savitz J, Lucki I, Drevets WC (2009) 5-HT(1A) receptor function in major depressive disorder. Prog Neurobiol 88:17-31

Scholzen T, Gerdes J (2000) The Ki-67 protein: from the known and the unknown. J Cell Physiol 182:311-322

Yang P, Arnold SA, Habas A, Hetman M, Hagg T (2008) Ciliary neurotrophic factor mediates dopamine D2 receptor-induced CNS neurogenesis in adult mice. J Neurosci 28:2231-2241

Zhang X, Andren PE, Greengard P, Svenningsson P (2008) Evidence for a role of the 5-HT1B receptor and its adaptor protein, p11, in L-DOPA treatment of an animal model of Parkinsonism. Proc Natl Acad Sci USA 105:2163-2168 